\section{Effects of changeover delay in concurrent schedules of reinforcement of key pecking by pigeons ${ }^{1}$}

AARON J. BROWNSTEIN and RICHARD L. SHUI.l. Universit!' of North Carolina at Greensboro, Greensboro, N.C. 27412

Examination of pigeons' kev-pecking performance, reinforced on concurrent variable-interval l-min variable-intenal 3-min schedules, as a function of the changeover delay revealed the following relationships. As the changeover delay was increased from o through $20 \mathrm{sec}$ (1) relative respense frequency on the key color associated with the l-min schedule increased, (2) relative time spent in the 1-min schedule increased, (3) obtained relative frequency of reinforcement in the 1 -min schedule increased, and (4) changeover rate decreased.

Concurrent operants are defined as "two or more cesponses on different topography al kast with respect lo locus. capable of being cxecuted with little mutual interterence al the same time or in rapid ahternation. under the combrol of separate prograning devices [Ferster \& Skinner, 1957]." The schedules of reinforcement provided by the separate programming devices represent concurrent schedules of reinforcement. Much research effort has been directed lowards determining the relationship between the parameters of the concurrent scliedules and the frequency of occurrence of the concurrent operants (see Catania, 1966). Several studies (Catania, 1963: Herrnstein. 1961: Shull \& Pliskoff, 1967) have demonstrated that when similar responses are maintained by concurrent variable-interval (VI) schedules of reinforcement, the relative frequency of occurrence of cach of the responses closely approximates the relative frequency of reinforcement of each of the responses. The relative frequency of occurrence of response is the frequency of occurrence of that response divided by the sum of the frequencies of occurrence of all of the concurrent responses. The relative frequency of reinforcement is determined in a similar manner. The near equivalence of the two measures appears to be critically dependent upon the inclusion of a changeover delay (COD) procedure (Catania. 1963: Herrnstein, 1961: Shull \& Pliskoff, 1967). A COD imposes a minimum delay between the occurrence of one response and the reinforcement of any concurrent response. A brief delay (approximately $2 \mathrm{sec}$ ) is generally sufficient to insure the near equivalence of the relative measures.

Shull \& Pliskoff (1967) examined the effects of a wide range of COD values on relative frequency of responding. Their results suggest that the relative frequency of responding may be a continuous function of the COD duration in conjunction with the programmed relative frequency of reinforcement.

The Shull and Pliskoff study differs fron most studies of concurrent schedules of reinforcement in several ways. Most notable among these was the use of the lever pressing of rats as the concurrent operants and brain stimulation as the reinforcing stimulus. The present experiment replicated the work of Shuil and Pliskoff, using the more conventional key pecking of pigeons as the concurrent operants and mixed grain as the reinforcing stimulus.

\section{SUBJECTS AND APPARATUS}

Three adult White Carneaux pigeons were maintained at $80 \%$ of their free-feeding body weights. All of the birds were experimentally naive at the start of the experiment.

A standard two-key experimental chamber was used (Lehigh Valley Electronics). The keys were $6 \frac{1 / 2}{2}$ in. apart and required a force of approximately $20 \mathrm{~g}$ to activate the microswitch behind the keys.

\section{PROCEDURE}

Throughout the experiment only pecks on the left key were reinforced by $3.5-\mathrm{sec}$ periods of access to mixed grain. All sessions, with the exception of the initial shaping session, occurred on successive days and lasted until 60 reinforcements had occurred. Over a series of 16 sessions, the schedule of reinforcement of pecking was shifted from continuous reinforcement to multiple VI 1-min schedules of reinforcement. During successive 2-min periods, the left key was alternately transilluminated with red and green lights. This condition was maintained for 10 sessions. This was followed by 10 sessions of concurrent VI 1.5-min. VI 1.5-min schedules of reinforcement. Independent and simultaneously operative tape programmers arranged reinforcements for pecks on the left key. Reinforcements assigned by one of the programmers occurred only for pecks on the red kcy.
The other programmer assigned reinforcements of pecks on the green key. Pecks on the right key, which was now illuminated with white light, alternated the colors on the left key. Each tape programmer ran continuously throughout the session, stopping only when a reinforcement was assigned and remaining stopped until the reinforcer had been presented. The concurrent schedules of reinforcement of pecks during red and green illumination were next shifted to VI 1-min and VI 3-min, respectively. These schedules were maintained for the remainder of the experiment. At this time, an ascending series of COD values was initiated. Each response on the right key started a timer or restarted the timer if it was in operation at the time of a response. A response on the left key could not be reinforced during the duration specified by the timer, although the programmers continued to operate and reinforcements could be assigned. Each COD value was in effect for 10 sessions. The values used are shown in Column 1 of Table 1.

\section{RESULTS AND DISCUSSION}

For each session, the relative frequency of responses emitted on the left key when it was illuminated with red light, the proportion of the session time during which it was so illuminated, and the proportion of reinforcements of pecking that occurred while the left key was

Table 1

Mean Performance Measures for Last Five Days Under Each COD Condition. Relative measures are with respect to the VI 1 -min schedule. Relative

Relative
COD Relative Reinforce- Relative

(Sec) Response ment Time CO/Min

\begin{tabular}{rrrrr}
\hline & & S1 & & \\
2 & .60 & .73 & .65 & 19.13 \\
5 & .73 & .75 & .76 & 4.89 \\
10 & .70 & .74 & .73 & 1.90 \\
15 & .92 & .90 & .93 & .36 \\
20 & .88 & .87 & .87 & .42 \\
& .98 & .98 & .97 & .06 \\
0 & .63 & .72 & .59 & 11.47 \\
2 & .71 & .76 & .75 & 4.30 \\
5 & .79 & .79 & .85 & 1.11 \\
10 & .86 & .86 & .88 & .32 \\
15 & .99 & .98 & .99 & .05 \\
20 & 1.00 & 1.00 & 1.00 & .00
\end{tabular}

\begin{tabular}{rcccc}
0 & .69 & .73 & .69 & 12.20 \\
2 & .77 & .77 & .80 & 4.03 \\
5 & .75 & .78 & .78 & 1.23 \\
10 & .78 & .81 & .79 & .80 \\
15 & .89 & .91 & .87 & .45 \\
20 & .96 & .98 & .98 & .11 \\
& & Nerage & & \\
0 & .64 & .73 & .64 & 14.27 \\
2 & .74 & .76 & .77 & 4.41 \\
5 & .75 & .77 & .79 & 1.41 \\
10 & .85 & .86 & .87 & .49 \\
15 & .92 & .92 & .91 & .31 \\
20 & .98 & .94 & .98 & .06 \\
\hline
\end{tabular}


illuminated with red light were computed. For each $S$. the mean of each of these measures for the last 5 days of each COD condition are presented in Table 1 in the columns headed Relative Responding, Relative Time, and Relative Reinforcements, respectively. The average of these measures for the three Ss is also presented. The rate of key color changes (pecks on the right key) for each $S$ and averaged over Ss during the last 5 days of each COD condition are presented in the columns headed Changeover Responses per Minute in Table 1.

The data presented in Table 1 clearly indicate that the relative response frequency, the relative reinforcement frequency, and the relative time spent with the key illuminated by red light increased systematically as the COD duration was increased. The rate at which the color and schedules were alternated on the left key decreased as the COD duration was increased.

These findings are in excellent agreement with those presented by Shull and Pliskoff. Consequently, the findings reported by Shull and Pliskoff do not seem to be critically dependent on the nature of the $S$ or reinforcer they used. Additionally, the present results indicate that the relative measures change continuously with increases in COD value beyond that needed to insure a close correspondence between the relative response measure and the programmed relative frequency of reinforcement. In the Shull and Pliskoff study only one COD value beyond the value required to obtain this correspondence was examined.

It is not entirely clear on the basis of the present study or the earlier work of Shull and Pliskoff whether or not changes in relative response frequency at COD values longer than those required to insure correspondence between relative response frequency and the programmed relative frequency of reinforcement are the consequence of the same factors responsible for changes in relative response frequency at shorter COD values. In both studies, there is a close correspondence between the relative response frequency and the obtained relative reinforcement frequency at all COD values greater than the value at which the correspondence with the programmed relative frequency is first observed. It is possible, therefore, that with higher COD values the changes in relative response frequency are more directly a consequence of changes in obtained reinforcement frequency produced by changes in COD value.

Stubbs \& Pliskoff (1969) found relative response frequency was essentially constant over a wide range of COD values when reinforcements were programmed so that obtained relative reinforcement frequencies equaled programmed at all COD values. These findings support the view that the changes in relative response rate found in the present study and in the Shull and Pliskoff study may result from the accompanying changes in reinforcement rate rather than the changes in COD directly.

Such an account, however, could not explain the changes in relative response frequency resulting from changes in COD values at the low end of the range examined by Shull and Pliskoff. They found continuous changes in relative response frequency with a constant obtained relative reinforcement frequency that was essentially equal to the programmed relative frequency.

More generally, the COD can be viewed as a member of a larger class of procedures that impose contingencies following changeovers. In this broader context. following each changeover with an electric shock (Todorov. 1969) and requiring 20 pecks on the changeover key for a schedule change (Stubbs \& Pliskoff, 1969) produced relative response frequencies in the richer schedule that were substantially higher than the obtained relative reinforcement frequencies. The reasons that the COD produces different effects from these other procedures under some conditions are not clear. Most likely, the COD involves complex contingencies that need to be further analyzed.

\section{REFERENCES}

CATANIA, A. C. Concurrent performances Reinforcement interaction and response independence. Journal of the Ixperimental Analysis of Behavior, 1963,6,253-263.

CATANIA, A. C. Concurrent operants. In W. K. Honig (Ed.). Operant behalior: Areas of research and application. New York: Appliton-Century-Crofts, 1966. Pp. 213-270.

IERSTER. C. B., \& SKINNER. B. I. Schedules of reinforcement. Non York: Applotondenturyerotis. 195

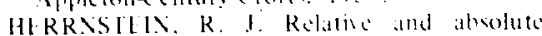
strength of response as a function of frequency of reinforcement. Journal of the F xperimental Analysis of Behavior, 1961. 4. 267-272.

SHULL, R. L., \& PLISKOIF, S. S, Changeover delay and concurrent sehedules: Some effects on relative performance measures. Journal of the Experimental Analysis of Bchavior, 1967. $10,517-527$.

STUBBS, D. A., \& PLISKOIF. S. S. Concurrent responding with fixed relative rate of reinforcement. Journal of the Fxperimental Analy sis of Behavior, 1969, 6, 887-895.

TODOROV. J. C. Concurrent performances: Effects of electric shock contingent upon changeovers. Paper presented at Eastern Psychological Association, Philadelphia. 1969. NOTE

1. This research was supported in part by a grant from the Research Council of the University of North Carolina at Greensboro. 